\title{
Power Quality Improvement utilizing PV Fed Unified Power quality Conditioner Based on UV-PI and PR-R Controller
}

\author{
R.Palanisamy, N. Durairaj, K.Vijayakumar, K.Saravanan
}

\begin{abstract}
Unifiedpowerqualityconditioners (UPQC's) allocate the lessening of voltage\& current-disturbances that might influence receptive electrical-loads while reimbursing the load reactive power. Different control systems have been proposed to assess the immediate yield voltage of the series dynamic power channel of the UPQC be that as it may, as a rule, these controllers just can remunerate a sort of voltage aggravation. This work proposes a PR controller for UPQCs which permits the heap current-harmonics and responsive capacity to be repaid at the framework side while maintaining a strategic-distance from the impact of voltage plunges, over-voltages and voltage-harmonics on the nearby loads. The controller qualities can be set up on-line without changing its fundamental structure. The execution of the proposeddcontroller has been assessed through simulationntests.
\end{abstract}

Keywords: UPQC, voltage dips, over voltages,vvoltage harmonics, currenttharmonics, reactive component.

\section{INTRODUCTION}

BLDC-engine-drive based on bridgeless-landsman PFC-converter with solitary-sensor \&diminished-stress on power-gadgets" was given by Praveen. -The conduction-misfortunes associated with diodes are diminished by BL-setup \&exchanging misfortunes of strong-state-switches of VSI are diminished by the utilization of low recurrence exchanging signals in electronic-substitution for the BLDCM. "-The front-end bridgeless-PFC based -Landsman-converter working in the discontinuous-inductortcurrent-mode (DICM) is utilized for controlling the DC interface voltage \& PFC" is attained usually with diminished-conduction misfortunes \&switch stress [1].

Superior-UPQC utilizing non-straight sliding mode and new exchanging elements control technique was introduced by Rajesh. The proposed non-straight sliding surface reflects the controlling activity of the DC-interface capacitor voltage with a variety of the framework's damping proportion and allows the DC-connect voltage to get a low overshoot and little settling time. This NLSMC method joins with a novel synchronous-reference outline (SRF) control strategy for generation of a fast and stable reference motion for both shunt \&series-converters. Another exchanging

Revised Version Manuscript Received on 10 September, 2019.

R.Palanisamy, Assistant Professor, Department of EEE, SRM Institute of Science and Technology, Chennai,Tamilnadu, India.

N. Durairaj, UG Research Scholar, Department of EEE, SRM Institute of Science and Technology, Chennai,Tamilnadu, India.

K.Vijayakumar, Professor, Department of EEE, SRM Institute of Science and Technology, Chennai, Tamilnadu, India.

K.Saravanan, Associate Professor, Department of EEE, SRM Institute of Science and Technology, Chennai,Tamilnadu, India. elements control system has been intended for the VSC of UPQC and this plan helps in the decrease of band infringement of the hysteresis band just as progress in the following conduct of UPQC amid framework perturbations [2].

Flexible-UPQC-given to 3P4W (three-phase-four-wire) distribution-frameworks utilizing a double-control-strategy was recommended by Rodrigo. This work introduces the examination, investigation and pragmatic execution of an adaptable UPQC, which can be associated in both three-stage three-wire and three-stage four-wire distribution frameworks for playing out the series-parallel electrical-line molding. Therefore, notwithstanding when just a three-stage three-wire control framework is accessible at a plant site, the UPQC can complete electrical cable pay for introduced loads that require an unbiased channel to operate [3].

PQ-enhancement in 3- $\Phi$-grid-associated-PV-framework with battery-storage was given by Rajan. The work introduces an investigation of PQ-enhancement in a 3- $\Phi$ network associated-PV-framework. The variable advance-perturb\& observe (VS-PO)-MPPT-plot has been utilized to compel the PV-generation achieve the most extreme power task. A BESS by means of a bi-directional DC/DC converter is acquainted in the DC-bus with keep up the DC voltage level at a consistent value [4].

Basic Control Strategies of the Active Filters inside a UPQC was displayed by Marian. UPQC comprises of joined shunt and arrangement dynamic power channels for improving both the power quality on the source side and on the heap side. This displays a basic strategy for controlling the series channel under uneven and contorted burden conditions by utilizing a three stage-locked-loop[5]. Utilization of UPQC for voltage-sag/ripple lessening in micro grid" was recommended by Parimi. Micro grid especially when worked in islanded working condition needs to keep up the power balance freely of a primary network because of firmly coupled generation, utilization and absence of interminable bus. Indeed, even in matrix associated mode responsive power pay is as yet testing because of straight and nonlinear burdens. In such manner, new procedures and gadgets for V AR pay in the miniaturized scale network are being researched[6].

UPQC for three stage four wire distribution-frameworks was given by Monika. The present work displays a job of 


\section{POWER QUALITY IMPROVEMENT UTILIZING PV FED UNIFIED POWER QUALITY CONDITIONER BASED ON UV-PI AND PR-R CONTROLLER}

UPQC in 3 stage 4 wire conveyance framework to improve the power quality. The UPQC is acknowledged by the coordination of arrangement and shunt dynamic power channels (APF) sharing a typical dc-bus capacitor [7]. Original control format for UPQC dependent on three-level (npc) inverter utilizing intelligent-frameworks" was displayed by Salim. The proposed UPQC can alleviate source current-harmonics and remunerate all voltage unsettling influences. It is planned by the joining of series and shunt dynamic channels (AFs) sharing a typical DC-bus-capacitor. The synchronous reference-frame (SRF) hypothesis is utilized to get the reference signals for the shunt APF and the power receptive hypothesis (P-Q hypothesis) for the series-APF. The shunt and arrangement dynamic power channel (APF) reference signals got from the control calculation and detected signs are infused in two keen controllers to create exchanging signals[8].

A 3P4P (three-phase-four-wire) grid-associated photovoltaic-framework utilizing a dual-UPQC" was proposed by Leonardo. This work proposes a photovoltaic (PV) control-generation- framework, which is executed by methods for multilevel- converters. The PV framework is associated with utility network and works as a UPQC. Accordingly, the PV-UPQC framework infuses dynamic power into the there-phase-grid and, all the while, performs dynamic electrical cable sifting, so as to improve the power quality. By utilizing double repaying methodology, the proposed PV-UPQC framework is executed by methods for two consecutive NPC converters having a similar dc-bus, which is straightforwardly associated with the PV array [9].

PQ-enhancement utilizing double-topology of UPQC" was given by Nikhil. This introduces the execution of SSSC for PQ-enhancement. As nonlinear burdens causes harmonics in framework and therefore the power quality gets reduced because of these non linear load[10]. "PQ-enhancement in power-system by utilizing SSSC" was exhibited by Vicky. As nonlinear burdens causes the harmonics in the system and therefore the PQ gets reduce because of this non linear $\operatorname{load}[11]$.

\section{PRINCIPLE OF UPQC}

Differing topologies have been proposed for UPQCs in single-stage setups, for example two IGBT half extensionssor multilevel-topologies, yet this paper center around the-regularly-utilized general-structure portrayed in fig--1. These functionalities can be done by applying differing control methodologies which can work in the time space, in the recurrence area or both. Time-domain strategies, for example, pq or dq based techniques, permit the quick pay of time-variation aggravations however make increasingly complex their particular remuneration. In this sense, recurrence area strategies are increasingly adaptable yet theirrdynamical reaction is slower.

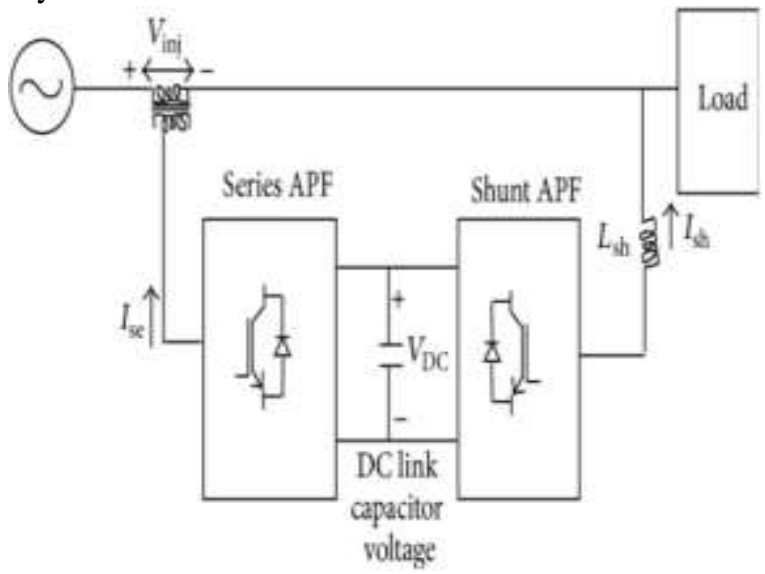

Fig.1. General-Structure of UPQC

This proposes another control method for UPQCs dependent on a Kalman separating approach. The proposed technique works both in the time and recurrence spaces permitting the particular remuneration for voltage and current-harmonics with quick dynamical reactions. Additionally, the effect on plunges and over-voltages can be constricted by applying theeproposed controller.

\section{SYSTEM DESCRIPTION}

UPQC is a combination of DVR and active-filter. The block diagram of UPQC systemmis shown in Fig.2. Closed loop PI controlled UPQC system is shown in the

fig. 3. Closed loop PR-R controlled UPQC system is shown in Fig.3. Receiving end voltage is compared with referencevvoltage to get the error. The output is applied to $\mathrm{PI} / \mathrm{PR}$ controller to update the pulse width.

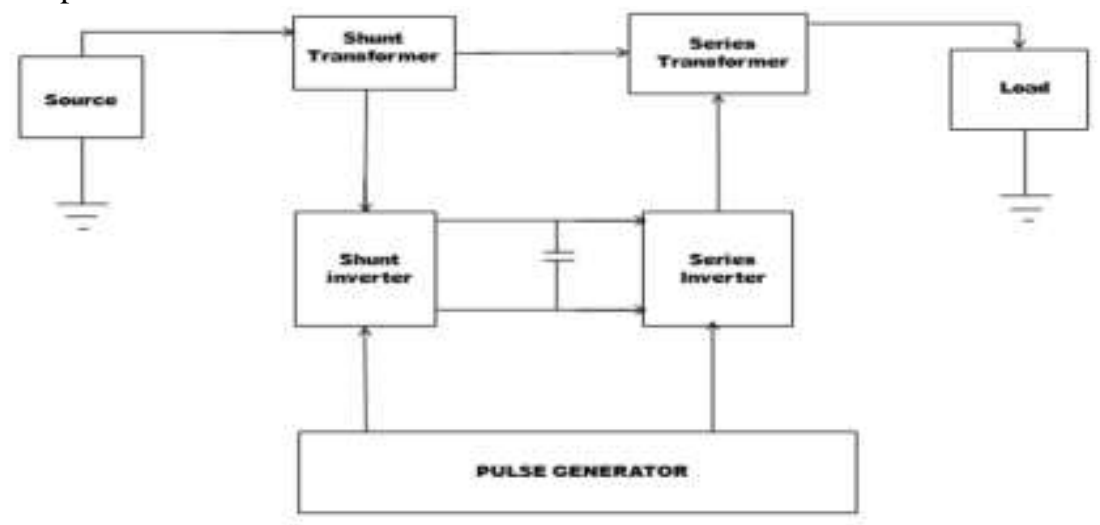

Fig.2. Simulation-Block-Diagram 


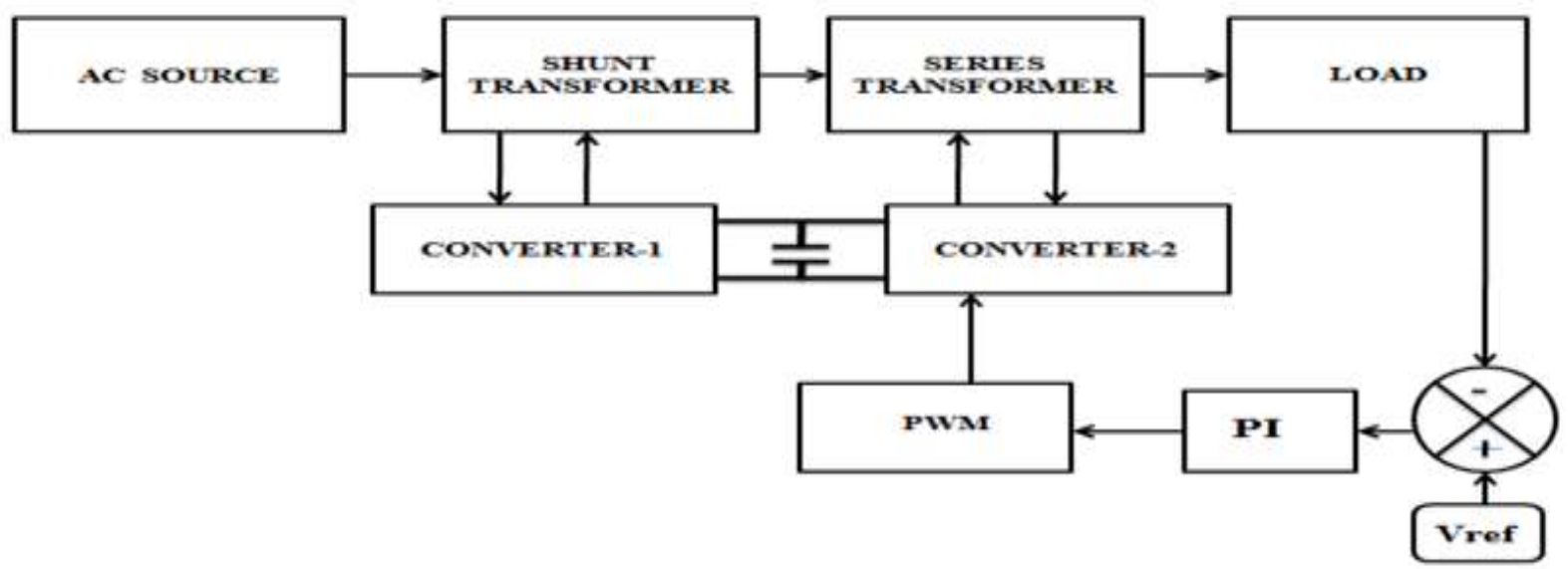

Fig-3. Block-diagram of PI-controlled-Closed-loop -ILBC with UPQC

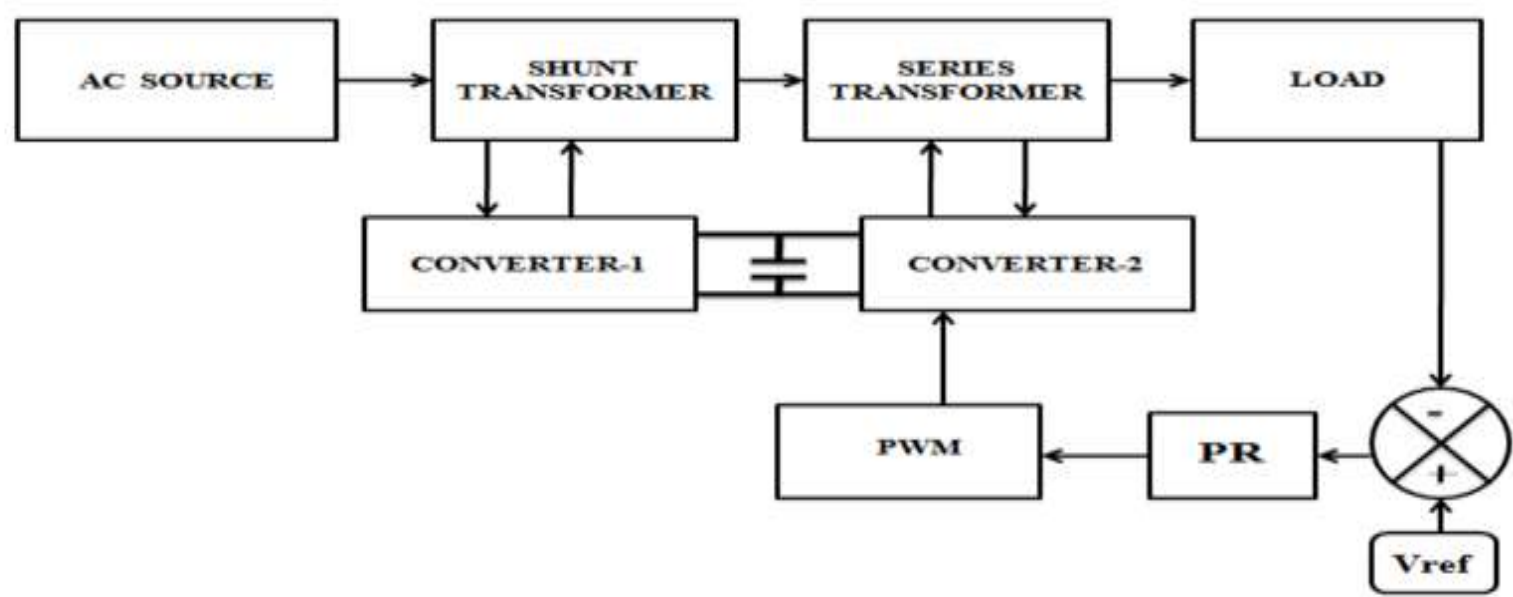

Fig.4.Block-diagram of PR-controlled-Closed-loop -ILBC with UPQC

The fig. 3 \& 4 shows Block-diagram of PI-controlled-Closed-loop -ILBC with UPQC and Block-diagram of PR-controlled-Closed-loop -ILBC with UPQC respectively.

\section{SIMULATION RESULTS}

Circuit diagram of PI controlled Closed loop ILBC with UPQC is delineated in Fig.5. Output voltage is delineated in Fig. 6 \&its value is $0.9 \mathrm{~V}$. RMS Output voltage is delineated in Fig.7 \&its value is 6800V. Real power is delineated in Fig. 8 \&its value is $4 * 10^{5} \mathrm{MW}$. Reactive power is delineated in Fig.9 \&its value is $6^{*} 10^{4}$ MVAR

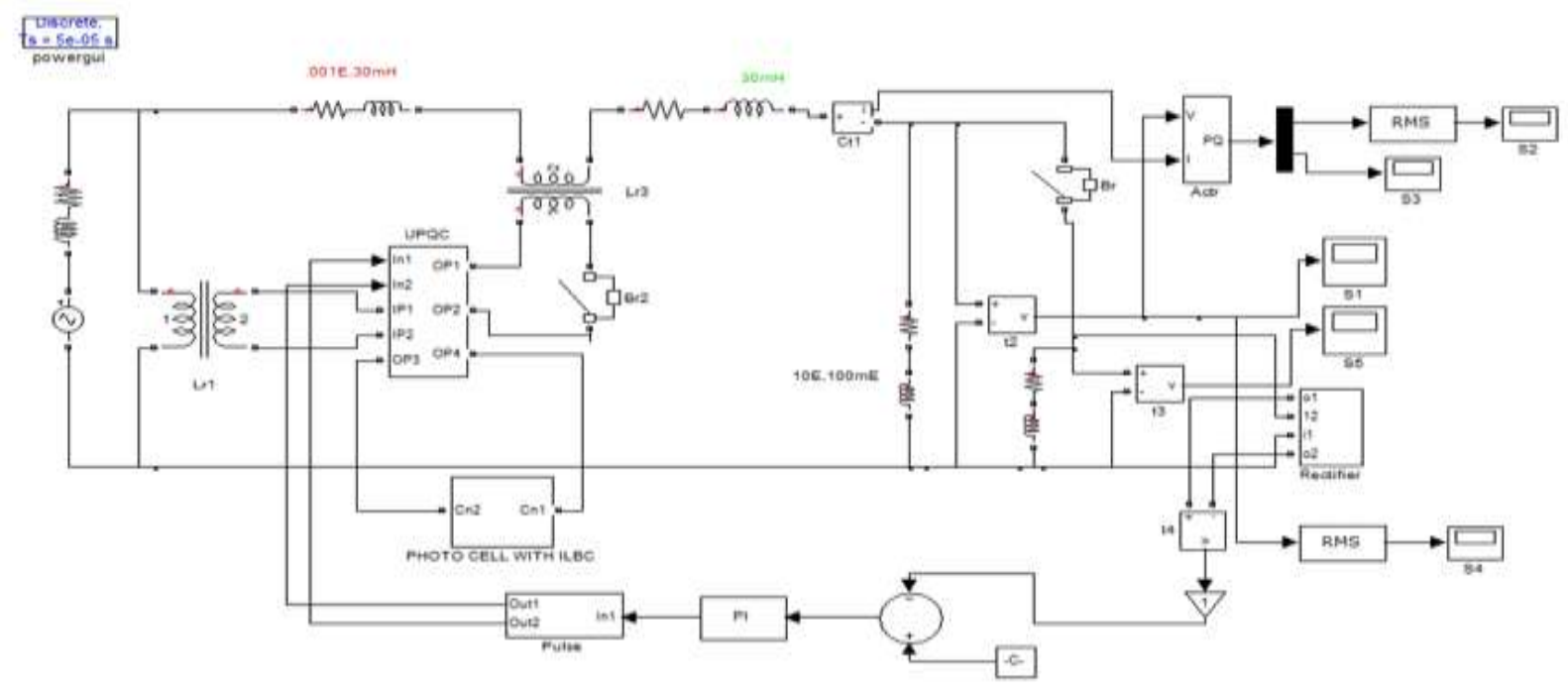

Fig.5. Circuit diagram of PI controlled Closed loop ILBC with UPQC 


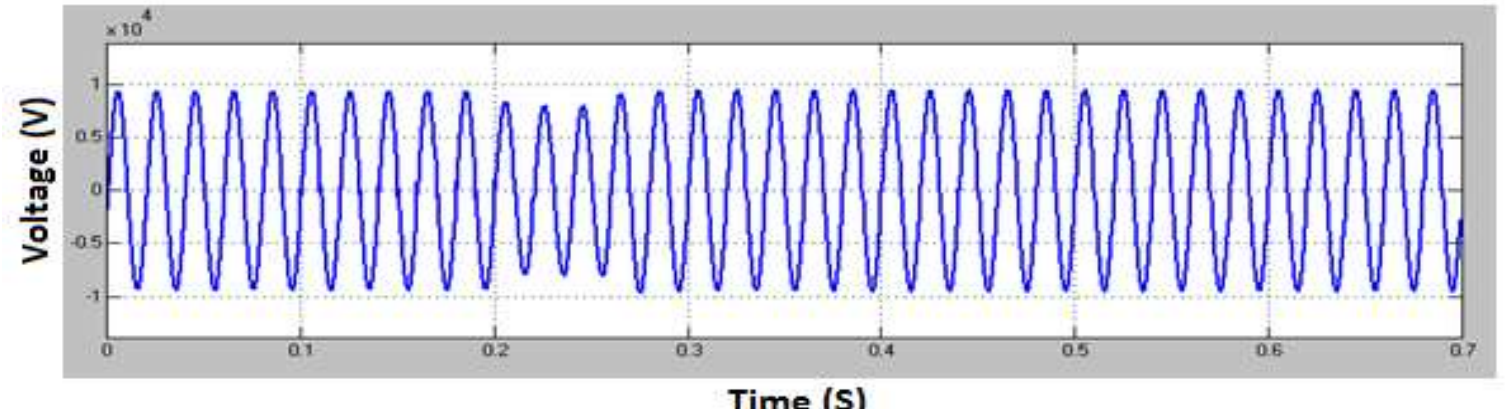

Fig.6. Output voltage of proposed system

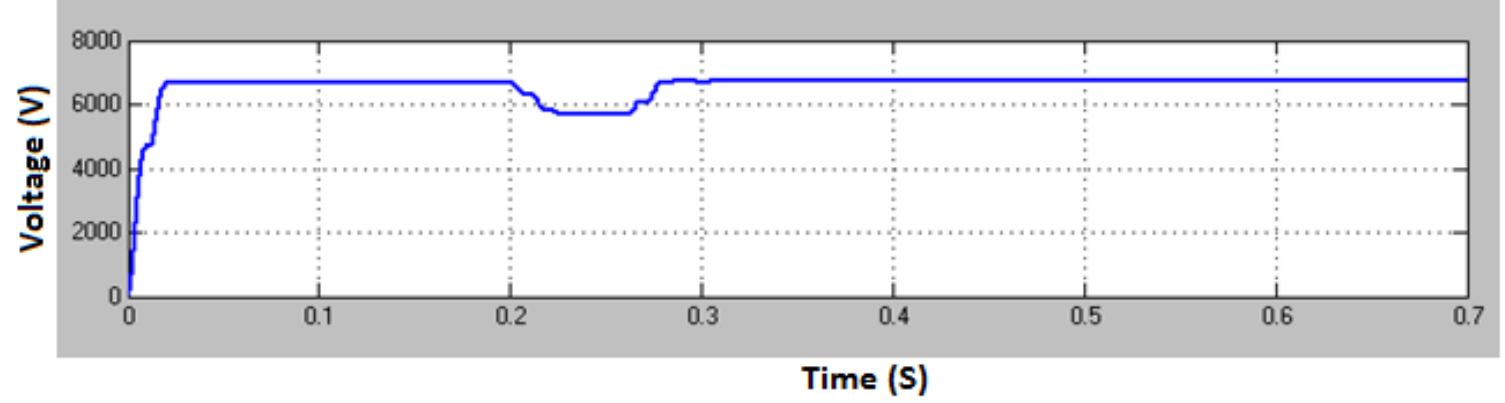

Fig.7.RMS output voltage

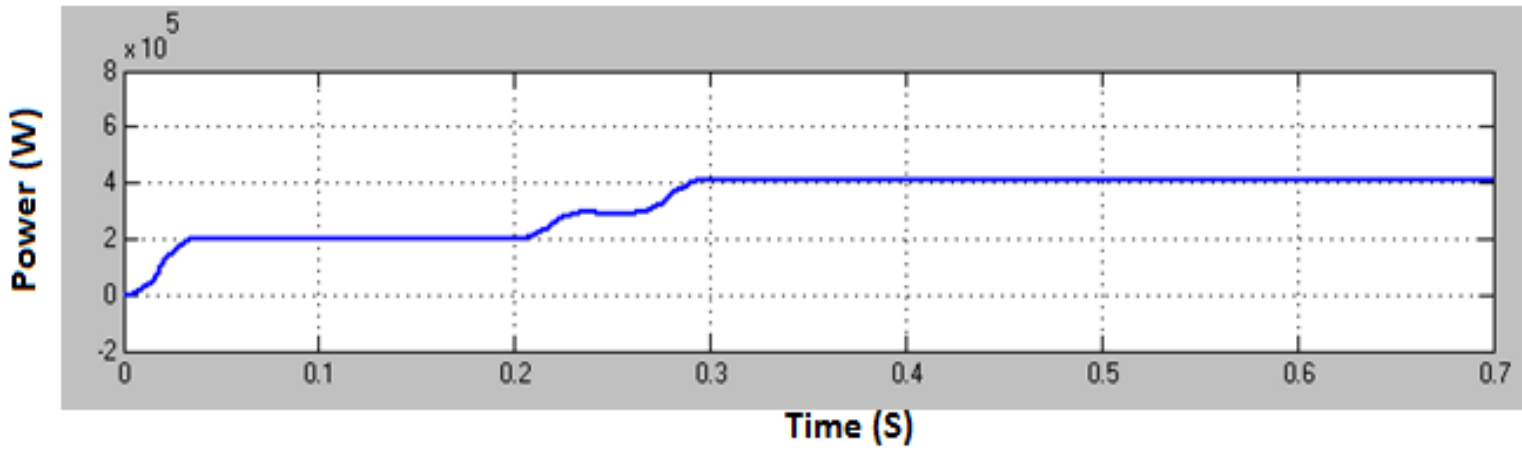

Fig.8.Real power

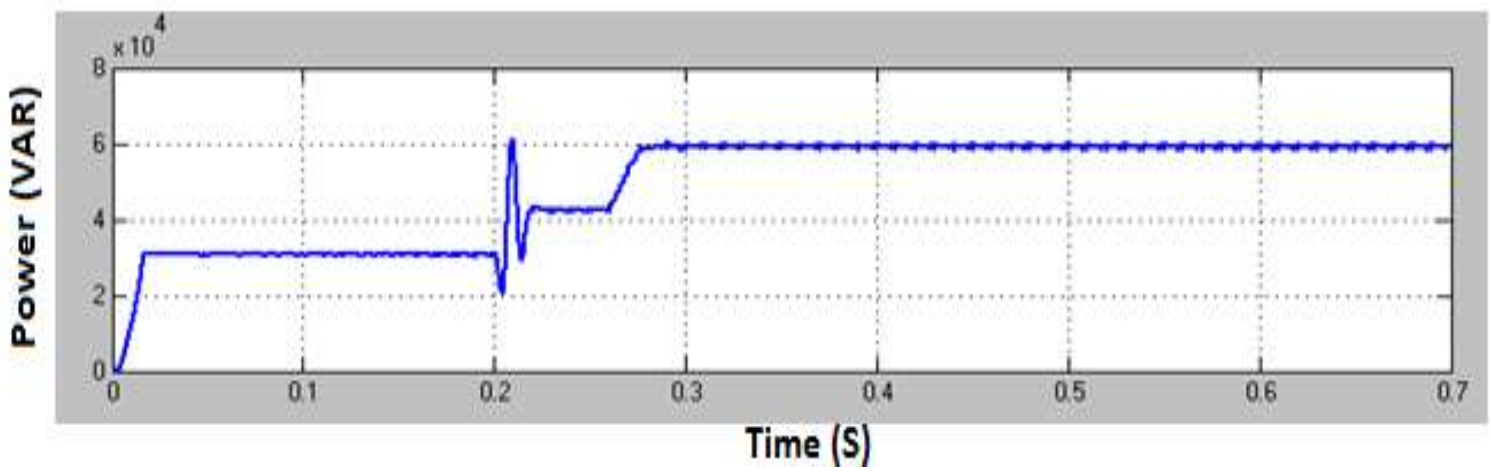

Fig.9.Reactive power

Circuit diagram of PI controlled Closed loop ILBC with UPQC is delineated in Fig.10. Output voltage is delineated in Fig. 11 \&its value is $0.8 \mathrm{~V}$ 


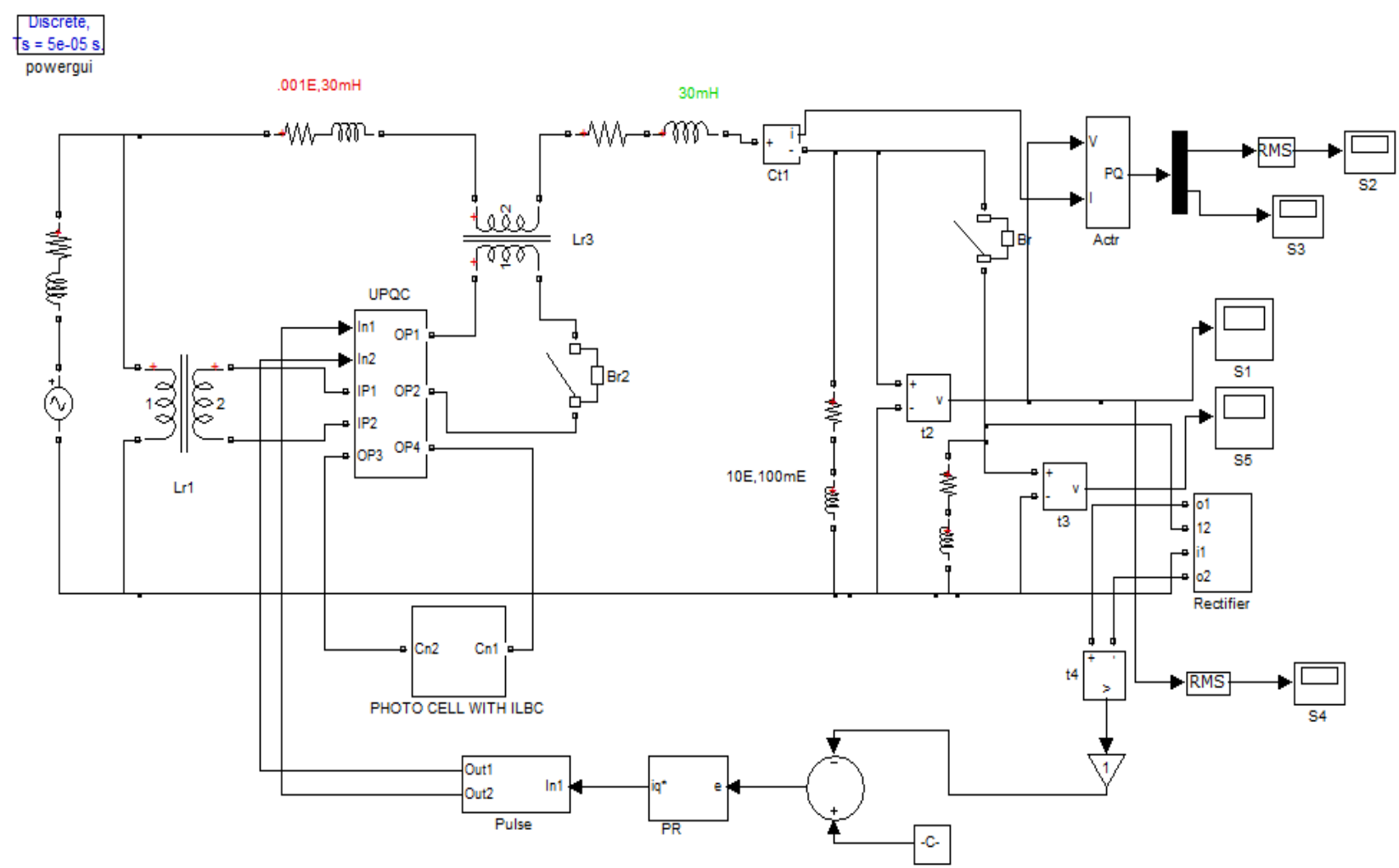

Fig.10. Circuit diagram of PR controlled Closed loop ILBC with UPQC

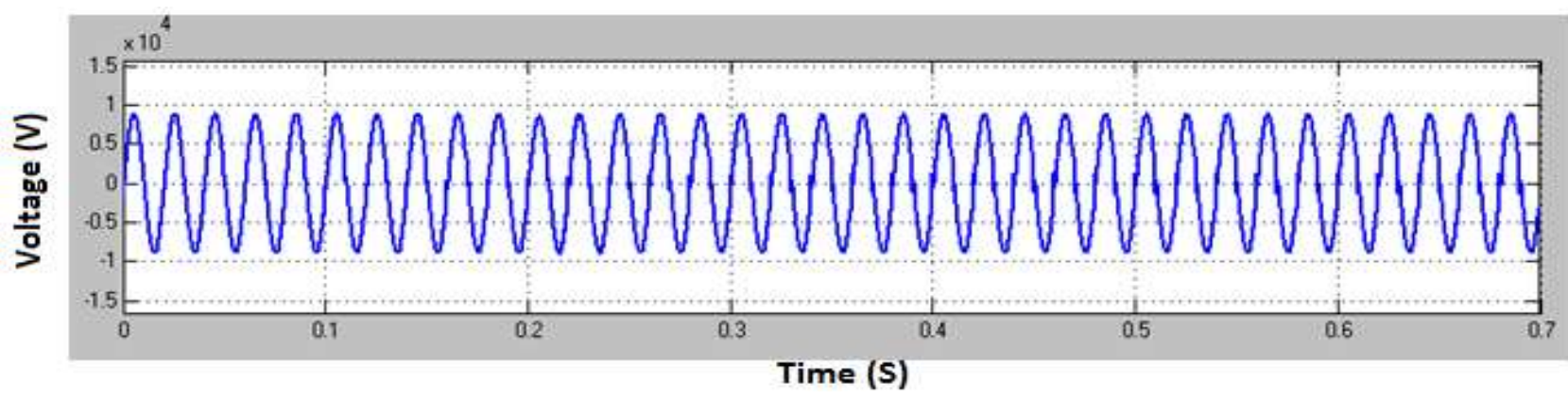

Fig.11. Output voltage of proposed system

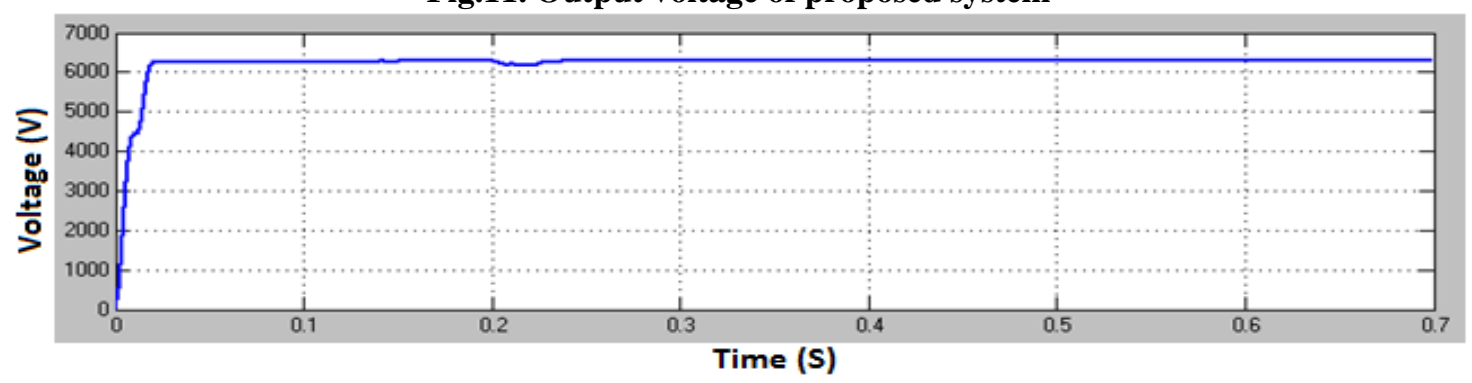

Fig.12. RMS output voltage

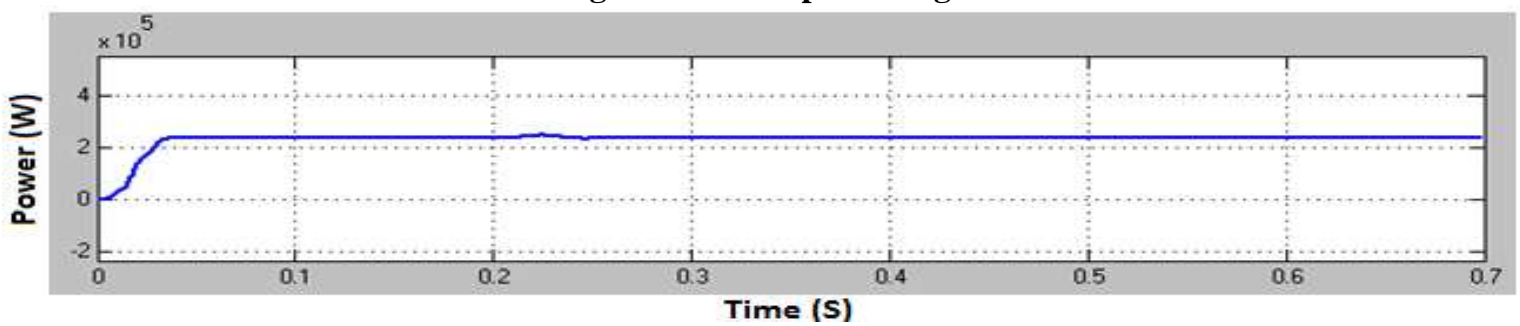

Fig.13. Real power 

BASED ON UV-PI AND PR-R CONTROLLER

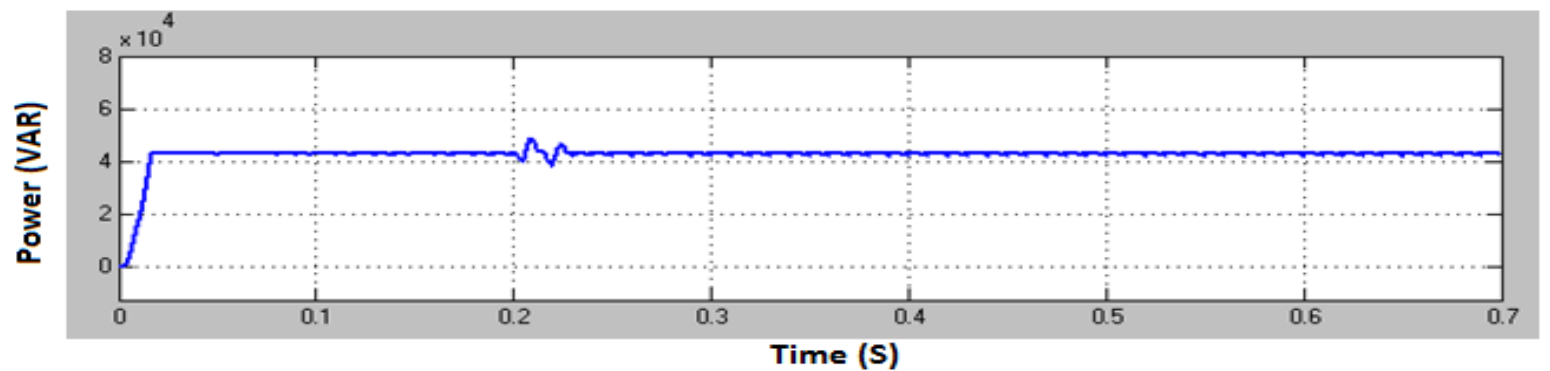

Fig.14.Reactive power

RMS Output voltage is delineated in Fig.12 \&its value is 6400 V. Real power is delineated in Fig. 13 \&its value is $2.5^{*}$ $10^{5}$ MW. Reactive power is delineated in Fig. 14 \&its value is $4.4 * 10^{4}$ MVAR.

Comparison of Time Domain Parameters using PI and PR is given in Table-1. By using PR, the rise time is reduced from $0.23 \mathrm{Sec}$ to $0.207 \mathrm{Sec}$; the "peak-time" is diminished from $0.26 \mathrm{Sec}$ to $0.21 \mathrm{Sec}$; the "settling-time" is reduced from $0.31 \mathrm{Sec}$ to $0.23 \mathrm{Sec}$; the "steady-state-error" is reduced from $5.3 \mathrm{~V}$ to $1.8 \mathrm{~V}$. Hence, PR controlled Closed loop ILBC with UPQC is superior to PI and PI controlled Closed loop ILBC with UPQC

Table-1 Comparisonnof Time DomainnParameters Using PI and PR Controllers

\begin{tabular}{|l|l|l|l|l|}
\hline Controller & $\begin{array}{l}\text { Rise } \\
\text { time } \\
(\mathrm{s})\end{array}$ & $\begin{array}{l}\text { Peak } \\
\text { time }(\mathrm{s})\end{array}$ & $\begin{array}{l}\text { Settling } \\
\text { time }(\mathrm{s})\end{array}$ & $\begin{array}{l}\text { Steady } \\
\text { state error } \\
(\mathrm{V})\end{array}$ \\
\hline PI & 0.23 & 0.26 & 0.31 & 5.3 \\
\hline PR & 0.207 & 0.21 & 0.23 & 1.8 \\
\hline
\end{tabular}

\section{EXPERIMENTAL RESULTS AND DISCUSSION}

Hardware circuit diagram of ILBC with UPQC is appeared in Fig 15. List of components is given in Table-2. The Hardware snap shot is delineated in Fig 16.

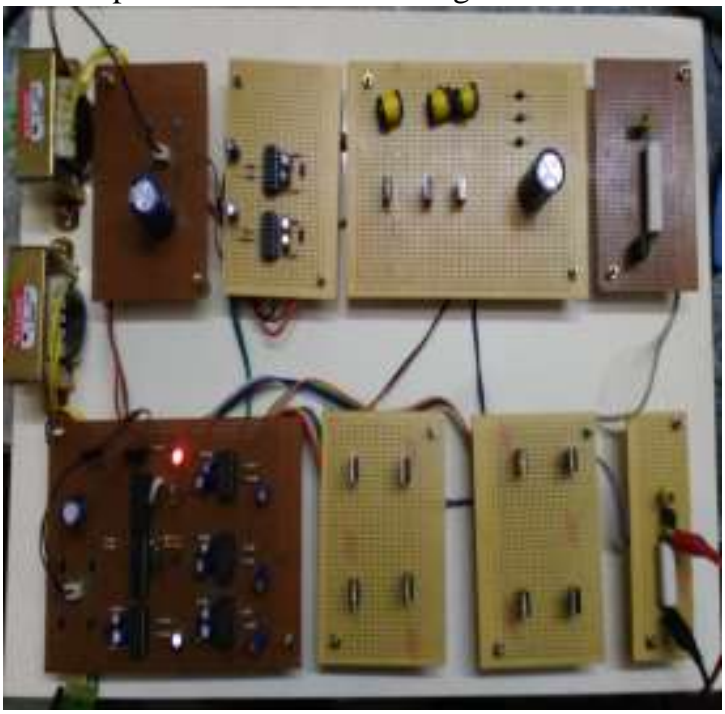

Fig.16. Experimental setup

Input voltage is appeared in Fig 17. Switching pulse for ILBC for $\mathrm{S} 1$ is shown in Fig 18. Voltage across ILBC is appeared in Fig 19.

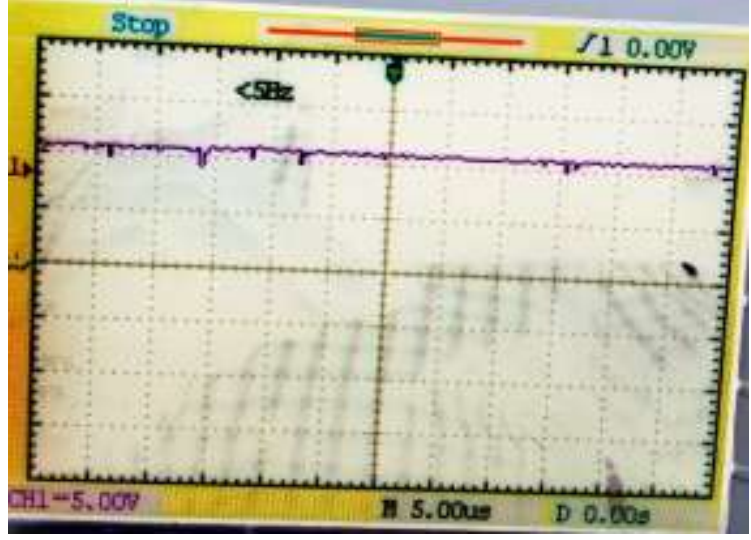

Fig.17. Input voltage applied

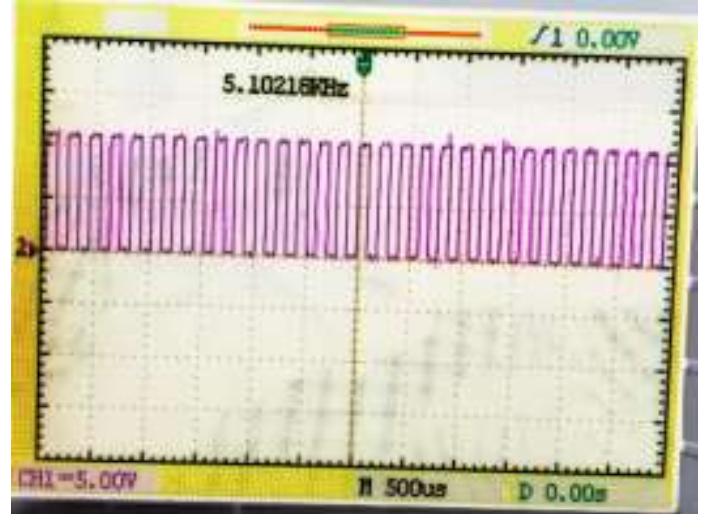

Fig 18 Switching pulse for ILBC for S1

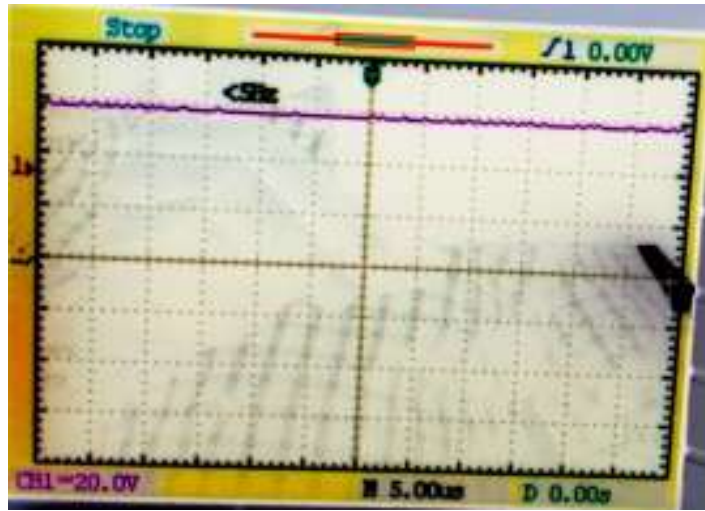

Fig 19 Voltage across ILBC

Switching pulse for inverter M1 is shown in Fig 20 Switching pulse for inverter M3 is appeared in Fig 21. Output voltage across RL load is delineated in Fig 22.

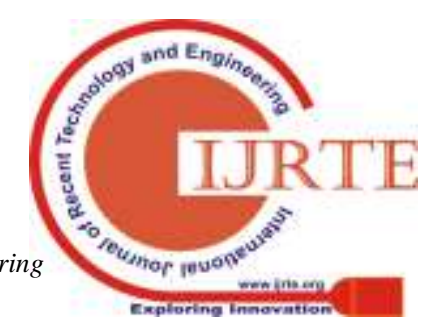




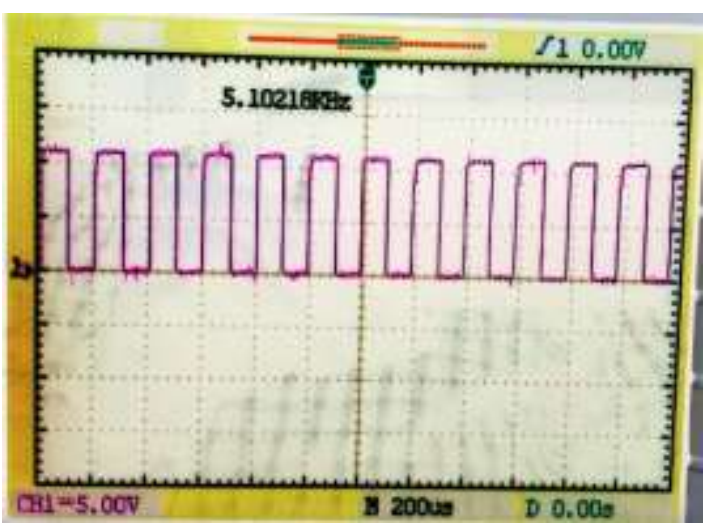

Fig 20 Switching pulse for inverter M1

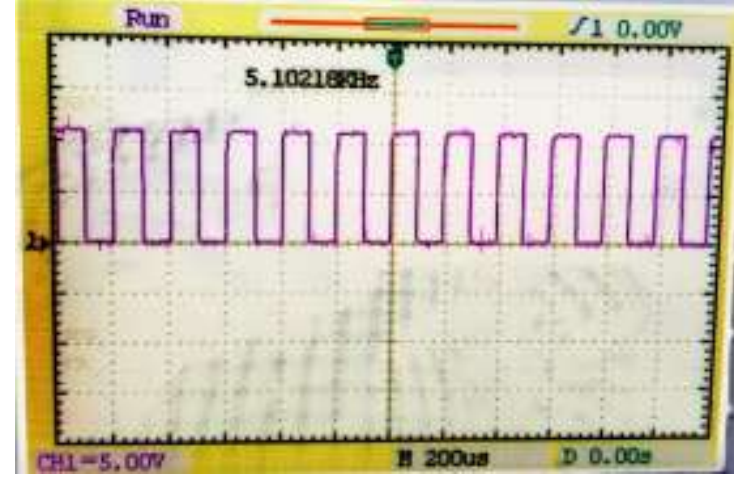

Fig 21 Switching pulse for inverter M3

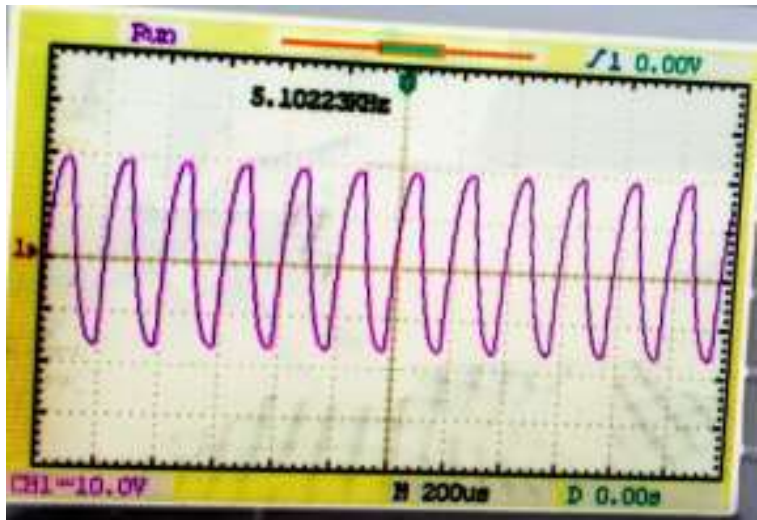

Fig 22 Output voltage across RL load

\section{CONCLUSION}

The 'UPQC' system is successfully designed modeled, by utilizing MATLAB SIMULINK. 'UPQC' has improved receiving-end voltage and provided time- harmonics to the load. The 'UPQC' systems in closed loop with PI and PR controllers are simulated and the results are presented. The "-steady-state-error" is reduced from $5.3 \mathrm{~V}$ to $1.8 \mathrm{~V}$. Therefore PR controller based 'UPQC' system may be a feasible substitute to the existing 'UPQC' system. The reduction in steady-state error is high in terms of PR controlled system. The settlingttime is reduced from 0.31 s to 0.23 seconds. The benefits of the recommended system are reduction in steady-state error and settling time. The negative-aspect of 'proposed- 'UPQC' -system' is it needs two-inverters. The scope of present work is the investigations on PI and PR controllers based 'UPQC' systems. The improvement in time response using FLC based 'UPQC' will be through in the future.

\section{REFERENCES}

1. D. C. Bhonsle, R. B. Kelkar, "Design and Simulation of Single Phase Shunt Active Power Filter", 2011 International Conference on Recent Advancements in Electrical, Electronics and Control Engineering.

2. V. Khadkikar, P. Aganval, A. Chandra, "A Simple New Control Technique For Unified Power Quality Conditioner (UPQC)", 2004 11th International Conference on Harmonics and Quality of Power.

3. H. Akagi, Y. Kanazawa, A. Nabae , "Generalized Theory of the Instantaneous Reactive Power in Three Phase Circuits", in Proc. IPEC-Tokyo'83 Int. Conf. Power Electronics, Tokyo, pp. 1375- 1386.

4. M.Kesler,E.Ozdemir,Senior Member, "Synchronous-Reference-Frame-Based Control Method for UPQC under unbalanced and distorted load conditions", IEEE transactions on industrial electronics, vol. 58, no. 9, september 2011.

5. I.Axente, M.Basu and M.Conlon, "dc link voltage control of UPQC for better dynamic performance", Electric Power Systems Research 81 (2011) 1815-1824.

6. Yash Pal, A. Swarup, Bhim Singh, "A control strategy based on UTT and Icos $\phi$ theory of threephase, four wire UPQC for power quality improvement " International Journal of Engineering, Science and Technology Vol. 3, No. 1, 2011, pp. 30-40.

7. S.Shankar, A.Kumar and W.Gao "Operation of Unified Power Quality Conditioner under Different Situation,' IEEE Proc. Power and Energy Society General Meeting, July 2011, pp.1-10.

8. M.Basu, M.Das and S. Dubey, "Comparative evaluation of two models of UPQC for suitable interface to enhance power quality," Electric Power Systems Research, Vol. 77, no. 7, pp.821-830. 2007.

9. Y. Kolhatkar and S. Das, "Experimental investigation of a single-phase UPQC with minimum VA loading," IEEE Trans. Power Del., vol. 22, no. 1, pp. 373-380, Jan. 2007.

10. X. Zhang, W. Zhang, Y. Lv, W. Liu, and Q. Wang, "Unified power quality conditioner with model predictive control," in Proc. 5th Int. Conf. Comput. Sci. Educ., Aug. 24-27, 2010, pp. 1239- 1244.

11. K. Vadirajacharya, P. Agarwal, and H. O. Gupta, "Unified constant frequency integration control of universal power quality conditioner," in Proc. Power Electron. Drive Energy Syst., Dec. 12-15, 2006, pp. 1-5.

12. A.Banerji,S.K. Biswas,B. Singh,"DSTATCOM Control Algorithms: A Review,'International Journal of Power Electronics and Drive System (IJPEDS), Vol.2, No.3, September 2012, pp. 285- 296.

13. S. R. Naidu, A. W. Mascarenhas and D. A. Fernandes "A Software Phase-Locked Loop for Unbalanced and Distorted Utility Conditions," IEEE POWERCON Nov.2004,vol. 2, pp. 1055- 1060.

14. C.Benachaiba, B.Ferdi ,"Voltage Quality Improvement Using DVR," Electrical Power Quality and Utilisation, Journal Vol. XIV, No. 1, 2008, pp.30-46.

15. F. Kamran and T. G. Habetler, "Combined deadbeat control of a series parallel converter combination used as a universal power filter," in Proc. Power Electron. Spec. Conf., Jun. 18-22, 1995, pp. 196-201. 